Original Research Article

\title{
Prescribing pattern and WHO core prescribing indicators in post- operative patients of Gynaecology department of a tertiary care teaching hospital
}

\author{
Bhanu P. Kolasani ${ }^{1}$, Prasanand Sasidharan ${ }^{2}$, Divyashanthi C. M. ${ }^{1}$, Annabelle Rajaseharan ${ }^{1}$, \\ Pandiamunian Jayabal ${ }^{1}$
}

\begin{abstract}
${ }^{1}$ Department of Pharmacology, Vinayaka Missions Medical College, Karaikal, Pondicherry, Tamil Nadu, India

${ }^{2}$ Department of Pharmacology, Dr. SM CSI Medical College, Karakonam,

Thiruvananthapuram, Kerala, India
\end{abstract}

Received: 03 December 2016 Accepted: 09 December 2016

*Correspondence to:

Dr. Bhanu P. Kolasani,

Email:

kolasanibhanu@yahoo.co.in

Copyright: (C) the author(s), publisher and licensee Medip Academy. This is an openaccess article distributed under the terms of the Creative Commons Attribution NonCommercial License, which permits unrestricted noncommercial use, distribution, and reproduction in any medium, provided the original work is properly cited.

\begin{abstract}
Background: Prescription pattern analysis is an essential tool to provide an insight regarding the existing drug usage and to ensure rational drug therapy. Even though drugs used for gynecological disorders are one of the commonly used, they are least studied in terms of prescribing patterns. Hence the present study was planned to analyze the prescribing pattern and WHO core prescribing indicators among post-operative patients of Gynaecology department in our institute.

Methods: A prospective observational study was conducted in 76 postoperative patients of Gynaecology department for a period of six months. Each prescription was analyzed for demographic data, total number and various categories of drugs prescribed, the percentage of individual drugs prescribed in each category, the dosage forms and the percentage of drugs prescribed by generic name, and from essential drug list were also analyzed.

Results: A total of 990 medications were prescribed among which antimicrobial agents $(32.52 \%)$ were the most commonly prescribed category followed by analgesics (19.60\%) and Intravenous fluids (13.53\%). Metronidazole $(27.02 \%)$ was the most commonly prescribed antimicrobial, Diclofenac $(68.04 \%)$ was the commonly prescribed analgesics and Ringer lactate $(38.81 \%)$ was the commonly prescribed Intravenous fluid. Most commonly prescribed antiulcer drug was ranitidine $(75.0 \%)$, antiemetic was Ondansetron (76.39\%). Majority of drugs (72.54\%) were prescribed by generic name. Average number of drugs per prescription was 13.03. Percentages of encounters with antibiotics were $32.52 \%$. The percentage of drugs prescribed from the National List of Essential Medicines (NLEM) was 82.16\%. Injection $(57.78 \%)$ was the most common drug formulation.

Conclusions: Antimicrobial agents and analgesics were the most commonly prescribed drugs. Prescription by generic name was high, usage of antibiotics and injections were also high and Poly-pharmacy was common, especially among antimicrobial agents. Prescribing according to the national essential list of medicines was high, which indicates rational prescription.
\end{abstract}

Keywords: Antimicrobial agents, Generic name, National list of essential medicines, Prescribing pattern, WHO core prescribing indicators

\section{INTRODUCTION}

The prescription is one of the most important therapeutic transactions between physician and patient.It is a written order for the medication to be used for diagnosis, prevention and treatment of specific patient directed by physician. $^{1,2}$
Monitoring prescriptions and drug utilization studies could identify the associated problems and provide feedback to prescribers. ${ }^{3}$ Developing countries have limited funds available for healthcare and drugs and it becomes very important to prescribe drug rationally so that the available funds can be utilized optimally. ${ }^{4}$ 
Irrational prescribing may account to professional and legal threat to a prescriber if done injudiciously as it indicates the prescriber's responsibility towards clinical care and safety of patient.

Essential drugs are those that satisfy the health care needs of the majority of the population; they should therefore be available at all times in adequate amounts and in appropriate dosage forms and at a price that individuals and the community can afford. This concept is intended to be flexible and adaptable to many different situations; exactly which drugs are regarded as essential remains a national responsibility. ${ }^{5}$

During the post-operative period, the normal physiological functions get regained. ${ }^{6}$ The process of healing from surgical trauma and the physical strength of the patients will get restored gradually. Prevention of infection should be a priority for health professionals as infections increase the mortality and morbidity of the patients. Post-operative management must be given for the completion of total recovery and even continues beyond the period of hospitalization until the patient returns to regular activities. ${ }^{7}$

There are very few studies which describe the utilization of drugs postoperatively in Gynaecology. The present article is an attempt to gain insight into prescribing patterns of drugs in post-operative patients of Gynaecology department.

\section{METHODS}

A prospective observational study was conducted in a total of 76 patients of post-operative ward in Gynaecology department in our teaching hospital for a period of six months.

\section{Inclusion criteria}

1. Patients aged more than 18 years.

2. Post-operative patients till their discharge from Gynaecology department of the hospital.

\section{Exclusion criteria}

1. Any patient who dies post-operatively before being discharged.

2. Patient absconded/discharged against medical advice.

3. Patient referred to higher centers.

A written informed consent to participate in the study was obtained from all the patients who participated in the study. The study protocol confirmed to the ethical guidelines of the 1975 Declaration of Helsinki, and ethical clearance was obtained from Institutional Ethical Committee before commencing the study.
Each prescription was analyzed for demographic data, total number and various categories of drugs prescribed, the percentage of individual drugs prescribed in each category, the dosage forms and the percentage of drugs prescribed by generic name, and from national essential drug list were also analyzed.

For the purpose of calculation, fixed dose combinations were considered as one single drug.

The percentage of drugs prescribed by generic name is calculated by dividing the number of drugs prescribed by generic name by total number of drugs prescribed, multiplied by 100 .

To analyze the percentage of drugs prescribed from the National List of Essential Medicines (NLEM) of India. Percentage is calculated by dividing number of products prescribed which are in essential drug list of India by the total number of drugs prescribed, multiplied by 100 .

The data was analyzed using descriptive analysis with the help of SPSS 21 version software.

\section{RESULTS}

In the present study, a total of 990 medications were prescribed to 76 patients among which the mean age of the patients undergoing gynecological surgery was $43.75 \pm 9.74$ years (mean \pm SD) and average haemoglobin was $9.22 \pm 1.75 \mathrm{gm} / \mathrm{dl}$ and random blood sugar was $95.7 \pm 16.61 \mathrm{gm} / \mathrm{dl}$. In our study, majority of 28 patients possessed blood group $\mathrm{B}+(43.16 \%)$ (Table 1). Most common presenting complaint was vaginal discharge followed by dysmenorrhea and dysfunctional uterine bleeding.

Table 1: Demographic profile of postoperative patients in Gynaecology department.

\begin{tabular}{|lll|}
\hline Parameters & Mean & SD \\
\hline Age & 43.75 years & 9.743419 \\
\hline Haemoglobin & $9.22 \mathrm{gm} / \mathrm{dl}$ & 1.753373 \\
\hline Random blood sugar & $95.7 \mathrm{gm} / \mathrm{dl}$ & 16.61356 \\
\hline & No. of cases & Percentage \\
& A+: 21 & $32.31 \%$ \\
Blood group & B+: 28 & $43.16 \%$ \\
& O $+: 12$ & $18.46 \%$ \\
& AB : 04 & $06.15 \%$ \\
& Total : 65 & $100 \%$ \\
\hline
\end{tabular}

Hysterectomy was done in $43.68 \%$ of total patients; other surgeries done with decreased frequency were emergency laparotomy $(6.58 \%)$, dilatation and curratage $(4.6 \%)$ and cervical biopsy (3.95\%). Miscellaneous $(2.63 \%)$ surgeries which include pyometra drainage and Purandare's cervicopexy. 
Table 2: Category wise prescription of drugs among post-operative patients of Gynaecology.

\begin{tabular}{|lll|}
\hline Drugs & $\begin{array}{l}\text { Total } \\
\text { number }\end{array}$ & $\begin{array}{l}\text { Total } \\
\text { percentage (\%) }\end{array}$ \\
\hline 1. Anti-microbial agents & 322 & 32.52 \\
\hline 2. Analgesics & 194 & 19.60 \\
\hline 3. Intra venous fluids & 134 & 13.53 \\
\hline 4. Anti-ulcer drugs & 120 & 12.12 \\
\hline 5. Anti-emetics & 72 & 7.23 \\
\hline $\begin{array}{l}\text { 6. Vitamins and mineral } \\
\text { preparations }\end{array}$ & 64 & 6.46 \\
\hline 7. Anti-spasmodic drugs & 23 & 2.32 \\
\hline 8. Anti-fibrinolytic drugs & 21 & 2.12 \\
\hline 9. Miscellaneous & 14 & 1.41 \\
\hline Sedatives & 07 & 0.70 \\
\hline Antiseptic drugs & 06 & 0.60 \\
\hline Hormonal preparations & 06 & 0.40 \\
\hline $\begin{array}{l}\text { Anti-hypertensive } \\
\text { drugs }\end{array}$ & 04 & 0.30 \\
\hline Anti-diabetic drugs & 03 & 0.30 \\
\hline Anti-histaminic drugs & 03 & 0.20 \\
\hline Laxatives & 02 & 0.10 \\
\hline Anti-thyroid drugs & 01 & 100 \\
\hline Total & 990 & \\
\hline
\end{tabular}

Out of total classes of drugs prescribed, Antimicrobials agents were the most common drugs $(n=322 ; 32.52 \%)$ (Table 3 and Figure 1). Among which, metronidazole either given parenterally $(16.77 \%)$ or orally $(10.25 \%)$ was the most commonly used antimicrobial followed by cefotaxime $(14.29 \%)$ which was followed by gentamicin $(12.42 \%)$ while amikacin $(0.31 \%)$ was the least used drug among the prescribed antimicrobials (Figure 2).

Table 3: Prescription of Anti-microbial agents among post-operative patients of gynaecology.

\begin{tabular}{|ll|}
\hline Drugs & Total percentage \\
\hline Inj. Metronidazole & $54(16.77 \%)$ \\
\hline Inj. Cefotaxime & $46(14.29 \%)$ \\
\hline Inj Gentamicin & $40(12.42 \%)$ \\
\hline Inj. Tetanus Toxoid & $38(11.80 \%)$ \\
\hline Tab. Metronidazole & $33(10.25 \%)$ \\
\hline Cap. Doxycycline & $29(9.01 \%)$ \\
\hline Tab. Mebendazole & $27(8.39 \%)$ \\
\hline Inj. Ampicillin & $24(7.45 \%)$ \\
\hline Cap. Amoxicillin & $13(4.04 \%)$ \\
\hline Inj. Ciprofloxacin & $08(2.48 \%)$ \\
\hline Tab. Ciprofloxacin & $06(1.86 \%)$ \\
\hline Tab. Levofloxacin & $03(0.93 \%)$ \\
\hline Inj. Amikacin & $01(0.31 \%)$ \\
\hline Total & $322(100 \%)$ \\
\hline
\end{tabular}

Cap = Capsule $;$ Tab = Tablet Inj $=$ Injection

The second most commonly prescribed group of drugs were analgesics $(n=194 ; 19.60 \%)$ out of which diclofenac either given parentrally $(38.14 \%)$ or orally $(29.90 \%)$ was the most commonly prescribed drug followed by pentazocine $(16.49 \%)$ and tramadol $(10.82 \%)$ (Table 4 and Figure 3). Paracetamol (4.64\%) was the least commonly prescribed drug in this category.

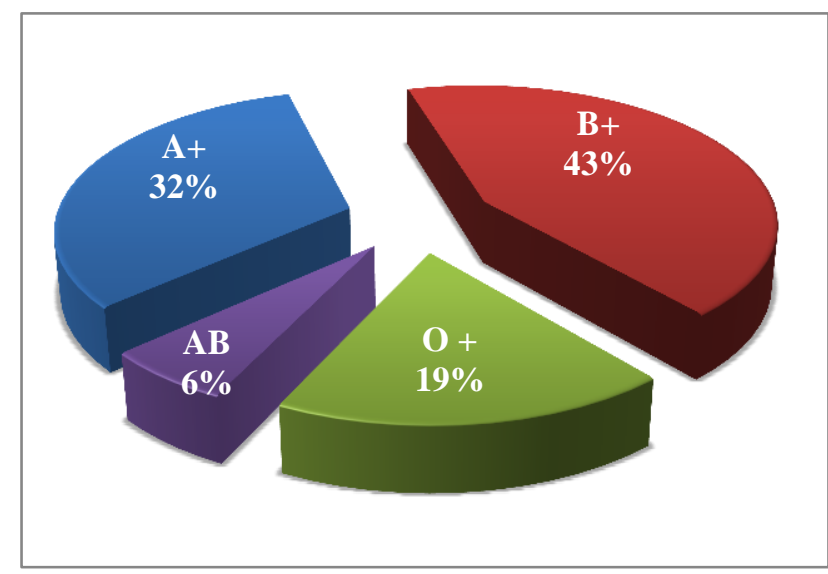

Figure 1: Blood groups among post-operative patients gynaecology.

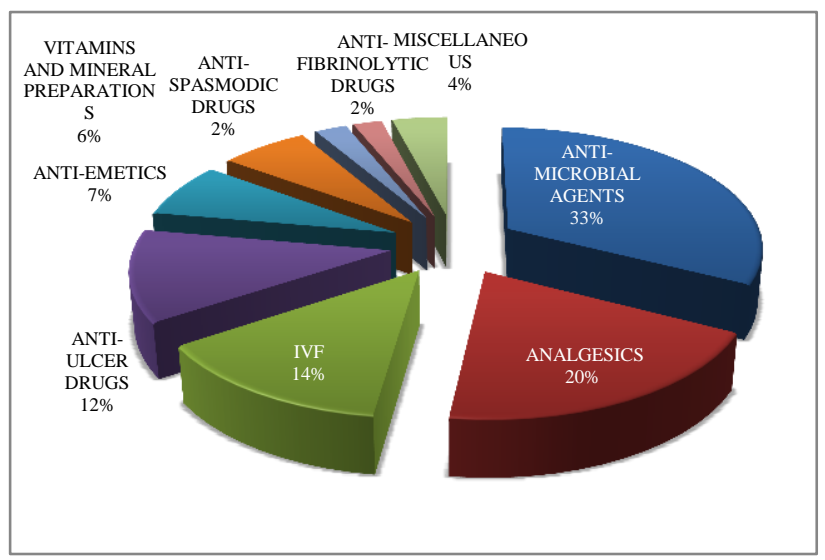

Figure 2: Category wise drug prescription among post-operative patients of gynaecology.

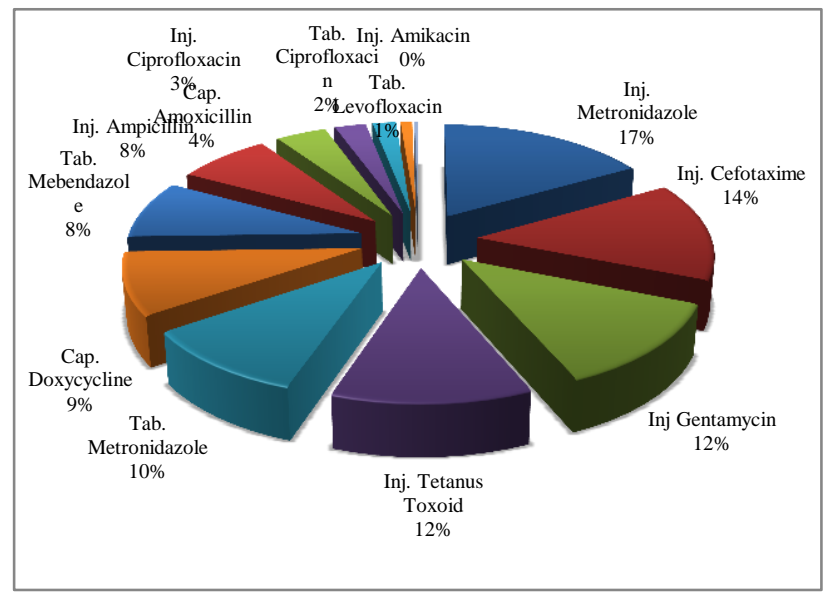

Figure 3: Prescription of anti-microbial agents among post-operative patients of gynaecology. 
Table 4: Prescription of analgesics among postoperative patients of gynaecology.

\begin{tabular}{|ll|}
\hline Drugs & Total percentage \\
\hline Inj. Diclofenac & $74(38.14 \%)$ \\
\hline Tab. Diclofenac & $58(29.90 \%)$ \\
\hline Inj. Pentazocine & $32(16.49 \%)$ \\
\hline Inj. Tramadol & $21(10.82 \%)$ \\
\hline Tab. Paracetamol & $09(4.64 \%)$ \\
\hline Total & $194(100 \%)$ \\
\hline
\end{tabular}

Tab $=$ Tablet Inj $=$ Injection

The third most prescribed drugs were Intravenous fluids $(n=134 ; 13.53 \%)$ among which ringer lactate $(38.81 \%)$ was the most commonly prescribed followed by dextrose normal saline $(32.84 \%)$ while normal saline $(28.36 \%)$ was the least commonly prescribed intravenous fluids (Table 5).

Table 5: Prescription of intra venous fluids among post-operative patients of gynaecology

\begin{tabular}{|ll|}
\hline Drugs & Total percentage \\
\hline Rl & $52(38.81 \%)$ \\
\hline Dns & $44(32.84 \%)$ \\
\hline Ns & $38(28.36 \%)$ \\
\hline Total & $134(100 \%)$ \\
\hline
\end{tabular}

Among the anti-ulcer drugs $(n=120 ; 12.12 \%)$ ranitidine whether given parenterally $(46.67 \%)$ or orally $(28.33 \%)$ was the most commonly prescribed drug followed by the proton pump inhibitor, pantoprazole (22.50\%). Esomeprazole $(0.83 \%)$ was the least prescribed drugs in this category (Table 6).

Table 6: Prescription of anti-ulcer drugs among postoperative patients of gynaecology.

\begin{tabular}{|ll|}
\hline Drugs & Total percentage \\
\hline Inj Ranitidine & $56(46.67 \%)$ \\
\hline Tab. Ranitidine & $34(28.33 \%)$ \\
\hline Inj. Pantoprazole & $27(22.5 \%)$ \\
\hline Syrup Antacid & $02(1.67 \%)$ \\
\hline Tab. Esomeprazole & $01(0.83 \%)$ \\
\hline Total & $120(100 \%)$ \\
\hline
\end{tabular}

$\mathrm{Tab}=$ Tablet $;$ Inj $=$ Injection

Table 7: Prescription of anti-emetics among postoperative patients of gynaecology.

\begin{tabular}{|ll|}
\hline Drugs & Total percentage \\
\hline Inj. Ondansetron & $55(76.39 \%)$ \\
\hline Inj. Promethazine & $17(23.61 \%)$ \\
\hline Total & $72(100 \%)$ \\
\hline
\end{tabular}

Tab = Tablet; Inj = Injection

With respect to anti emetics $(n=72 ; 7.23 \%)$ that were prescribed to post-operativeGynaecology patients ondansetron $(76.39 \%)$ was most commonly prescribed followed by promethazine $(23.61 \%)$ (Table 7$)$.

Among the vitamin and mineral preparations $(n=64$; $6.46 \%)$, ferrous sulphate $(28.13 \%)$ was the most commonly prescribed which was closely followed by vitamin B complex $(23.44 \%)$ and later by calcium $(18.75 \%)$ and folic acid $(1.56 \%)$ was the least prescribed in this group (Table 8).

Table 8: Prescription of vitamin and minerals among post-operative patients of gynaecology.

\begin{tabular}{|ll|}
\hline Drugs & Total percentage \\
\hline Cap. Ferrous sulphate & $18(28.13 \%)$ \\
\hline Cap. Vitamin B Complex & $15(23.44 \%)$ \\
\hline Tab. Calcium & $12(18.75 \%)$ \\
\hline Tab. Vitamin C & $09(14.06 \%)$ \\
\hline Inj. Iron sucrose & $06(9.38 \%)$ \\
\hline Cap. Vitamin B 12 & $03(4.69 \%)$ \\
\hline Tab. Folic Acid & $01(1.56 \%)$ \\
\hline Total & $64(100 \%)$ \\
\hline
\end{tabular}

Cap = Capsule; Tab = Tablet; Inj $=$ Injection

The next group of drug was anti-spasmodic drugs $(n=23$; $2.32 \%)$, in which dicyclomine either given parenterally $(60.87 \%)$ or orally $(39.13 \%)$ was the only drug prescribed.

Table 9: Prescription of anti-spasmodics among postoperative patients of gynaecology.

\begin{tabular}{|ll|}
\hline Drugs & Total percentage \\
\hline Inj. Dicyclomine & $14(60.87 \%)$ \\
\hline Tab. Dicyclomine & $09(39.13 \%)$ \\
\hline Total & $23(100 \%)$ \\
\hline
\end{tabular}

Tab = Tablet; Inj = Injection

Table 9 shows As far as anti-fibrinolytics $(n=21 ; 2.12 \%)$ are concerned, tranexamic acid either givenparenterally $(57.14 \%)$ or orally $(42.86 \%)$ was the only drug prescribed (Table 10).

Table 10: Prescription of anti-fibrinolytic drugs among post-operative patients of gynaecology.

\begin{tabular}{|ll|}
\hline Drugs & Total percentage \\
\hline Inj. Tranexamic Acid & $12(57.14 \%)$ \\
\hline Tab. Tranexamic Acid & $09(42.86 \%)$ \\
\hline Total & $21(100 \%)$ \\
\hline Tab = Tablet; Inj = Injection & \\
\hline
\end{tabular}

Miscellaneous drugs include sedatives like diazepam $(\mathrm{n}=14 ; 35 \%)$, antiseptics like betadinepessaries $(\mathrm{n}=7$; $17.5 \%)$, hormonal preparations like medroxy progesterone acetate $(n=6 ; 15 \%)$, among the antihypertensive drugs the most commonly prescribed being losartan $(\mathrm{n}=4 ; 10 \%)$ anti-diabetic drug like metformin $(n=3 ; 7.5 \%)$, anti-histaminic drug cetirizine $(n=3 ; 7.5 \%)$, 
laxative like lactulose $(n=2 ; 5 \%)$ and anti-thyroid drug carbimazole $(n=1 ; 2.5 \%)$ (Table 11$)$.

Table 11: Prescription of miscellaneous drugs among post-operative patients of gynaecology.

\begin{tabular}{|ll|}
\hline Drugs & Total percentage \\
\hline Sedatives & $14(35 \%)$ \\
\hline Antiseptic drugs & $07(17.5 \%)$ \\
\hline Hormonal preparations & $06(15 \%)$ \\
\hline Anti-Hypertensive drugs & $04(10 \%)$ \\
\hline Anti-Diabetic drugs & $03(7.5 \%)$ \\
\hline Anti-Histaminic drugs & $03(7.5 \%)$ \\
\hline Laxatives & $02(5 \%)$ \\
\hline Anti-Thyroid drugs & $01(2.5 \%)$ \\
\hline Total & $40(100 \%)$ \\
\hline
\end{tabular}

Table 12: Prescription of drugs according to the dosage forms among post-operative patients of gynaecology.

\begin{tabular}{|lll|}
\hline Dosage Form & Number & Percentage (\%) \\
\hline Injections & 572 & 57.78 \\
\hline Infusions & 195 & 19.70 \\
\hline Tablets & 134 & 13.54 \\
\hline Capsules & 78 & 7.88 \\
\hline Pessaries & 07 & 0.71 \\
\hline Syrups & 04 & 0.40 \\
\hline Total & 990 & 100 \\
\hline
\end{tabular}

Table 12 brings out the various dosage forms of the drugs that were prescribed in this study which depicts that the majority three dosage forms were injections $(n=572$; $57.78 \%)$ followed by infusions $(n=195 ; 19.70 \%)$ which were followed by tablets $(n=134 ; 13.54 \%)$. The least prescribed dosage form was as syrup $(n=4 ; 0.40 \%)$. In our study, the percentage of drugs prescribed by generic name was found to be $72.54 \%$ and the percentage of drugs prescribed from NLEM was found to be $82.16 \%$ (Table 13).

Table 13: WHO core drug prescribing indicators among postoperative patients in gynaecology.

\begin{tabular}{|lll|}
\hline Sr. No & $\begin{array}{l}\text { Indicator } \\
\text { Average number of antibiotics per }\end{array}$ & Value \\
\hline 2 & $\begin{array}{l}\text { Avescription } \\
\text { prent }\end{array}$ & $72.54 \%$ \\
\hline 3 & $\begin{array}{l}\text { Percentage of drugs prescribed by } \\
\text { generic name }\end{array}$ & $32.52 \%$ \\
\hline 4 & $\begin{array}{l}\text { Percentage of encounters with } \\
\text { antibiotic prescribed }\end{array}$ & $\begin{array}{l}\text { Percentage of encounters with an } \\
\text { injection prescribed }\end{array}$ \\
\hline 5 & $\begin{array}{l}\text { Percentage of drugs prescribed } \\
\text { from essential drug list }\end{array}$ & $82.16 \%$ \\
\hline
\end{tabular}

\section{DISCUSSION}

Even though, there were few studies done in India which analyzed the pattern of drug use in patients of postoperative Gynaecology department, majority of them analysed only antimicrobial or analgesics drug prescription pattern considering both Obstetrics and Gynaecology procedures. To the best of our knowledge, the present study was first of its kind that has comprehensively analyzed, various classes of drugs used in patients of post-operative Gynaecology department in a teaching hospital situated in coastal region of south India.

The overall data of 76 patients who underwent surgery in the gynecology department of a tertiary care teaching hospital was collected. In our study, the mean age of patients undergoing Gynaecological surgeries was 43.75 \pm 9.74 years which was in accordance with the studies conducted by Ali SA et al which showed patients were close to average menopausal age group and the reports werein contrast to the previous studies conducted by Khan M L et al, Alam S N et al, Javaid M et al which showed a lower age group less than 40 years averaging $33.94 \pm 12.51$ years. $^{8-11}$

The most commonly done surgery was Hysterectomy of $43.68 \%$ of total patients. This value was higher than the findings Shah BK and Shah VN in which it was $11.30 \%{ }^{12}$ Unlike our study, in these studies, the patients were from low socioeconomic status, less educated, rural area.

In the present study antibiotics were prescribed to all 76 patients post operatively $(100 \%)$. The purpose of antibiotic usage in post-operative patients was prophylactic to prevent post-operative infection at the surgical site rather than a definite treatment. Overall, antimicrobials were the most commonly prescribed drugs in our study which was in agreement with other studies done by Shah BK et al and Shivong A et al. ${ }^{12,13}$

Among antimicrobials, metronidazole $(27.02 \%)$ was the most commonly prescribed drug in our study followed by cefotaxime $(14.29 \%)$. This was in relevance with other studies conducted by Lofmark $\mathrm{S}$ et al since most of the gynaecological infections are anaerobic and metronidazole being the drug of choice for anaerobic organisms. ${ }^{14}$ Our study was in contrast to study done by Shah BK and Shah VN which showed that ciprofloxacin was maximally used $(60.90 \%)$ followed by ampicillin $(54.54 \%)$ and metronidazole $(39.69 \%) .^{12}$

Metronidazole was followed by usage of cephalosporins which are proven agents for the treatment of soft tissue infections and post-surgical prophylaxis. ${ }^{15}$ Cephalosporins are potent drugs to minimize the surgical site infections but regarding the resistance against cephalosporins with increased use were also reported. ${ }^{16}$ However, the use of antimicrobials in combination often 
was irrational and without any evidence. Few combinations were still in use among physicians like injection ceftriaxone and injection amikacin, despite these drugs have similar spectrum of action which covers mostly gram negative organisms. Just like another example where Ampicillin and Cloxacillin which is irrational; because the combination belongs to beta lactam antibiotics which act on same site by same mechanism offering no synergism or additive effects when combined. ${ }^{17}$

But caution must be implemented while prescribing antimicrobials as their empiric or irrational use could facilitate emergence of antibiotic resistance and increase the cost of treatment. Enormouus number of studies done in India had reported a greater use of ampicillin, metronidazole, gentamicin, cefazolin and ciprofloxacin for gynecology post-surgical prophylaxis. ${ }^{18,19}$ Since the number of antibiotics per patient was higher this indicates that more antibiotics were used as prophylactic management. It was used a broad spectrum therapy to prevent all types of infection which leads to increased incidence of adverse drug reactions, more treatement cost and finally ending up with drug resistant bacterial strains.

There were few drawbacks noticed like over prescription of antibiotics by the clinicians and inappropriate use is still a common practice in many hospitals in developing countries. Prescription of antibiotics without evidence of culture and sensitivity tests is another major problem, which results in poor patient compliance. All these practices result in emergence of multiple antibiotic resistant strains of organisms. We recommend that there is a need for strict antibiotic prescription policies which has to be developed by a collaborative effort involving pharmacologists, physicians, surgeons and microbiologists and target must be aimed to minimize the incidence of resistance to antimicrobial agents and also to promote infection control practices and rational antibiotic utilization.

Amongst the analgesics, diclofenac sodium was the most commonly used analgesics followed by pentazocine and tramadol which was consistent with the findings of Dashputra AV and Badwaik RT and Vlahovic et al but contrast to Kolawole IK et al showed where pentazocine was the most commonly used analgesic followed by tramadol which was $86.4 \%$ and $13.6 \%$ respectively. ${ }^{20-22}$ However, the use of NSAIDs particularly diclofenac for the management of postoperative pain is still controversial. In a study done by Henry et al., it was found that ibuprofen was the most common drug prescribed among analgesics. ${ }^{23}$. Even antispasmodics (dicyclomine) had been substantially prescribed in our study which was primarily used for relieving dysmenorrhea.

As post-operative pain is one of the major problems after any surgery, use of an analgesic had almost become mandatory following every surgery. Large varieties of analgesics were available in the market which may lead to the problem like irrational prescription. For various reasons, effective treatment of acute postsurgical pain presents and unique challenges for medical practitioners. ${ }^{24}$ The appropriate pain control is associated with reduced incidence of postoperative complications. We recommend that anesthetists should be more involved in postoperative analgesia prescriptions and should strengthen postoperative pain management.

Intravenous fluids were the next most commonly used drugs. Ringer's lactate $(38.81 \%)$, was the most common i.v. fluid used in our study and these findings we consistent with previous study conducted by Salman MT et al where again ringer lactate (46.91\%) was predominantly used. $^{25}$ It is necessary to manage the electrolyte imbalances post operatively, for which ringer lactate is the preferred IVF. Administration of intravenous fluids may be one of the reasons causing increase in the average number of drugs per patient.

In our study, the average number of drugs per prescription was 13.03 which were in range of 4 to 15 . This is higher in comparison to the finding of Salman MT et al which was $4.8 .^{25}$ The administration of intravenous fluids may be one of the reasons causing increase in the average number of drugs per patient. In postoperative patients among all departments, the usage of poly pharmacy is quiet common especially among antimicrobial agents and awareness to avoid poly pharmacy is must for cost effective treatment which can be dealt with SAIL and TIDE approaches. SAIL: Simple drug regimen, adverse effects knowledge, clear Indication, List of drug name and dosage in chart, kept safe. TIDE: allow Time to address medication issues, understand Individual variability, avoid potential dangerous Drug-drug interactions, and educate patients regarding treatment.

The average number of antibiotics per prescription in our study was 4.24 , which was higher compared to the study conducted by Abula $\mathrm{T}$ and Durbin WA where it was $2.18 .^{26}$ In the present study, the percentage of average number of generic drugs prescribed was $72.54 \%$ which indicates a developed trend of drug prescription which are safer, rational, efficacious and comparatively economical to the patients. Increasing generic prescribing would rationalize the use and reduce the cost of the drugs. ${ }^{27,28}$ The prescription of generic drugs needs to be promoted on national level.

Percentage of encounters with an injection prescribed was $57.78 \%$ and infusions was $19.70 \%$ in our study which makes a total of $77.48 \%$ which is low compared to the previous studies conducted by Agarwal et al which showed an average of $88.13 \% .{ }^{29}$ The ideal percentage of injections prescribed according to WHO must be between $13.4 \%-24.1 \%$, but in our study it was found to be more higher since post-operative gynaecology patients were kept in intravenous line till they were recovered and 
discharged. Use of more number of injectable drugs was observed by Patel et al while in some studies done by Rehan et al reported use of less number of injectable drugs in north India. ${ }^{30,31}$ Most of the patients received antimicrobials intravenously for the first five to seven post-operative days. Patients were then shifted to oral formulations for better compliance and cost effectiveness.

Essential drugs were those that satisfy the health care needs of the majority of population. In our study, $(82.16 \%)$ were prescribed from the Essential Medicines WHO Model List which was similar to other studies like Agarwal et al $(85.1 \%)$ and Falguni et al $(92.8 \%){ }^{29,32}$ Prescribing according to the national essential list of medicines was high, which indicates rational prescription.

In spite of such NLEM oriented prescriptions, irrational prescriptions still exists. We put forth few recommendations to curb irrational prescribing like the need to follow ethical guidelines on a proper prescription of drugs and to ensure that the patients utilize drugs only on prescription and in right formulations. Creating awareness by continuing medical education programs regarding rational use of drugs. Routine auditing of prescriptions will be helpful for the improvement of proper use of drugs which in turn can provide good quality health care economically. Need for National Antibiotic policy which prevents inadvertent use of antimicrobials in the form of self-prescription by patients or pharmacists is essential.

Our study is useful in decreasing the irrational prescription, which helps to decrease the morbidity and health care burden in the society. This report is intended to be a step in the broader evaluation of safety and efficacy of drug prescription in surgical wards of a teaching hospital.

\section{CONCLUSION}

Antimicrobial agents and analgesics were the most commonly prescribed drugs. Prescription by generic name was high, usage of antibiotics and injections were also high and Poly-pharmacy was common, especially among antimicrobial agents. Awareness to avoid poly pharmacy is required for cost effective treatment. Prescribing according to the national essential list of medicines was high, which indicates rational prescription.

\section{ACKNOWLEDGEMENTS}

Our heartfelt thanks to all the staff of Department of Obstetrics and Gynaecology for their constant support throughout the study without which this study would not be possible.

\section{Funding: No funding sources}

Conflict of interest: None declared

Ethical approval: The study was approved by the Institutional Ethics Committee

\section{REFERENCES}

1. Benet LZ. Goodman and Gilman's Principles of Prescription order Writing and Patient Compliance Instructions. The pharmacological basis of therapeutics. In: Gilman AG, Rall TW, Nies AS, Taylor P. $8^{\text {th }}$ ed, New York: Pergamon press. 1991;2:1640-49.

2. Lewis VA. Prescription writing and Drug regulation. Pharmacology and Therapeutics for dentistry. In: Yogiela JA, Dowd FJ, Neidle EA. $5^{\text {th }}$ ed., India: Mosby Publishers; 2005:865-879.

3. Shewade D, Pradhan S. Auditing of prescriptions in a government teaching hospital and four retail medical stores in Pondicherry. Indian $\mathbf{J}$ Pharmacol. 1998;30:408-10.

4. Shankar PR, Partha P, Dubey AK, Mishra P, Deshpande VY. Intensive Care Unit drug utilization in a teaching hospital in Nepal, Kathmandu Univ Med J. 2005;3:130-7.

5. $9^{\text {th }}$ Report of the WHO expert committee: The use of Essential Drugs. WHO TRS 895, 2000. 2012.[Cited March 2012]. Available from: www.who.int/iris/bitstream/10665/42373/1/WHO_T RS_895.pdf

6. Patil S, Padma L, Veena DR. Drug utilization study of antimicrobials in postoperative wards in a teaching hospital Int Res J Pharm App Sci. 2012;2(5):59.

7. Swamy RM, Venkatesh G, Nagaraj HK. A prospective drug utilization evaluation of analgesics and pain assessment in postoperative urological patients in a Tertiary care hospital. Biomedical Research. 2010;21(4):401-5.

8. Ali SA, Soomro AG, Tahir SM, Memon AS. Prospective basic clinical audit using minimal clinical data set. JAyub Med Coll Abbottabad. 2010;22,1:34-6.

9. Khan MLZ, Arain A, Qureshi FA. Patient's selection in limited resources a stimulus for improving care. PJS. 2008;24(4):35-8.

10. Alam SN, Rehman S, Zaidi SMR, Manzar S. Audit of general surgical unit: Need for self evaluation. PJS. 2007;23(2):141-4.

11. Javaid M, Masood Z, Iqbal SA, Sultan T. Pak J Med Sci. 2004;20(4):311-4.

12. Shah BK, Shah VN. Antimicrobial use by Department of Obstetrics and Gynaecology of a tertiary care hospital: Analysis for rationality and other aspects. J Obstet Gynecol Ind. 2004;54(4):38792.

13. Shivong A, Phouthavane T, Lundborg CS, Sayabounthavong K, Syhakhang, Wahlstrom R. Reproductive tract infections among women attending a Gynecology outpatient department in Vientiane, Lao PDR. Sexually Transmitted Diseases. 2007;34(10):791-5.

14. Lofmark S, Edlund C, Nord CE. Metronidazole is still the drug of choice for treatment of anaerobic infections. Clinical Infectious Diseases. 2010;50:1623. 
15. Ministry of Health and Family Welfare Government of India. National Guidelines on Prevention, Management and control of Reproductive tract infections including Sexually Transmitted infections. 2012.

16. Adu A, Armour CL. Drug utilization review of thethird generation cephalosporins. Focus on ceftriaxone, ceftazedime and cefotaxime. Drugs. 1995; Sept;50(3):423-39.

17. Gupta N, Sharma. D, Garg SK, Bhargava VK. Auditingof prescriptions to study utilisation of antimicrobials in a tertiary hospital. Indian $\mathbf{J}$ of Pharmacol. 1997;29:411-5.

18. Srishyla MV, Nagarani MA, Vekantraman BV. Drug utilization of antimicrobials in the in-patient setting of a tertiary hospital. Ind J Pharmacol. 1994;26:2827.

19. Uppal R, Gupta S, Shobha G. Drug utilization of antimicrobials in caesarian section. J Obstet Gynecol Ind. 1991;41:346-9.

20. Dashputra AV, Badwaik RT. Utilization of analgesics in perioperative cases of teaching hospital. Int J Med Pharm Sci. 2013;3:14-9.

21. Vlahovic-Palcevski V, Wettermark B, Bergman U. Quality of nonsteroidal anti-inflammatory drug prescribing in Croatia (Rijeka) and Sweden (Stockholm). Eur J Clin Pharmacol. 2002;58(3):20914.

22. Kolawole IK. Post-operative apin management following caesarean section in university of Ilorin Teaching Hospital (UITH), Ilorin, Nigeria. WAJM. 2003;22(4):305-9.

23. Henry D, Lim LL, Garcia Rodriguez LA, Perez Gutthann S, Carson JL, Griffin M. Variability in risk of gastrointestinal complications with individual nonsteroidal anti-inflammatory drugs: results of a collaborative meta-analysis. BMJ. 1996;312(7046):1563-66.

24. Kehlet H, Dahl JB. Anaesthesia, surgery, and challenges in postoperative recovery. Lancet. 2003;362(9399):1921-8.

25. Salman MT, Akram MF, Rahman S, Khan FA, Haseen MA, Khan SW. Drug prescribing pattern in surgical ward of a teaching hospital in North India. 2008;5(2):5-6.

26. Abula T, Desta Z. Drug prescribing in surgical and gynaecological wards of a teaching hospital. 19941995 (unpublished data).

27. Quick JD, Hogerzeil HV, Velasquez G, Rago L. Twenty-five years of essential medicines. Bull: WHO. 2002;80(11):913-14.

28. Ravi Shankar P, Partha P, Nagesh S. Prescribing patterns in medical outpatients. Int $\mathrm{J}$ Clin Pract. 2002;56:549-51.

29. Agarwal JM, Patel NM, Vaniya HV, Trivedi HR, Balat JD. Drug utilization study in post-operative patients in obstetrics and gynaecology ward of a tertiary care teaching hospital. J Clin Exp Res. 2014;2:103-9.

30. Patel V, Vaidya R, Naik D, Borker P. Irrational drug use in India: A prescription survey from Goa. J Postgrad Med. 2005;51(1):9-12.

31. Rehan HS, Lal P. Drug prescribing pattern of interns at a government healthcare centre in northern India. Trop Doct. 2002;32:4-7.

32. Falguni. Use of antimicrobial prophylaxis for obstetric and gynecological surgeries and sensitivity pattern of infective organisms. World journal of pharmacy and pharmaceutical sciences. 2014;3(6):1170-80.

Cite this article as: Kolasani BP, Sasidharan $\mathrm{P}$, Divyashanthi CM, Rajaseharan A, Jayabal P. Prescribing pattern and WHO core prescribing indicators in post-operative patients of Gynaecology department of a Tertiary Care Teaching Hospital. Int J Basic Clin Pharmacol 2017;6:53-60. 